International Journal of Forensic Science \& Pathology (IJFP)

ISSN 2332-287X

\title{
An Autopsied Case of a Neonate with the Anomalous Origin of Total Coronary Arteries from the Pulmonary Artery
}

\author{
Zhenglian C, Shen C, Chen $\mathrm{X}^{*}$ \\ Case Report \\ Department of Forensic Pathology, Tongji Medcial College, Huazhong University of Science and Technology, Wuhan, 430030 China.
}

\begin{abstract}
Coronary artery anomaly is not a very common disease. A neonate with the origin of total coronary arteries from the pulmonary artery (TCAPA) is extremely rare and fetal, which has not been yet reported in China. Here an autopsied case of TCAPA is reported to provide reference for the medical colleagues. A female infant died 9 hours after born when the hypoxia symptoms presented, although the rescue measures had already done. The cause of death was identified as TCAPA by forensic pathologists. In this case, TCAPA was ignored by the doctors because of non specifically clinical presentations. If it had been diagnosed, surgery should have been done immediately to be able to supply enough blood for the heart.
\end{abstract}

Keywords: Congenital Heart Disease; Coronary Artery Anomaly; Total Coronary Arteries Origin From Pulmonary Artery (TCAPA); Coronary Angiography.

\begin{abstract}
*Corresponding Author:
Xinshan Chen MD PhD,

Department of Forensic Pathology, Tongji Medcial College, Huazhong University of Science and Technology, Hangkong Rd. 13\#, Wuhan, 430030 China.

E-mail: xinshanchen@hotmail.com; xschen@mails.tjmu.edu.com
\end{abstract}

Recieved: August 13, 2014

Accepted: January 19, 2015

Published: January 20, 2015

Citation: Zhenglian C, Shen C, Chen X (2015) An Autopsied Case of a Neonate with the Anomalous Origin of Total Coronary Arteries From the Pulmonary Artery. Int J Forensic Sci Pathol. 3(1), 77-78. doi: http:// dx.doi.org/10.19070/2332-287X-1500047

Copyright: Chen $\mathbf{X}^{\odot}$ 2015. This is an open-access article distributed under the terms of the Creative Commons Attribution License, which permits unrestricted use, distribution and reproduction in any medium, provided the original author and source are credited.

\section{Introduction}

Coronary artery anomaly (CAA), which includes the origin, course and structure, exists in $0.9-1.4 \%$ of patients in pediatric population [1-2]. The anomalous origin of one coronary artery (left or right coronary artery, ALCAPA or ARCAPA) is commonly reported [2-4]. Total origin of the coronary arteries from pulmonary artery (TCAPA), however, has been rarely presented $[5,6]$. This paper introduced a case of an infant with TCAPA, who suffered from severe hypoxia. The pathophysiological, clinical presentations, diagnosis, and treatment were briefly discussed as well.

\section{Case history}

The victim was a female infant, who was born to her 29-year-old mother at 39 weeks of gestation, and died 9 hours after elective caesarean section B- scan ultrasonography showed that the fetal heart rate was 144 beats per minute, and umbilical cord entangled around the fetal neck 1 coil. Apger score was 3, 0, 3 at 1, 5, 10 min respectively. The umbilical cord entanglement around neck was 3 coils, but no sign of constrictions was found. The physical examination showed heart beat at 60 beats per minute and respiration of 16 breaths per minute; the pulses were absent in the extremities, which were pale and cold. The diagnosis of "severe asphyxia or congenital heart disease" was in consideration. Heart rate and breath returned following emergency intubation, peak airway, and transtracheal naloxone and adrenaline injection. Then the baby was transferred to another hospital for further therapy. The blood analysis showed acidosis and oxygen saturation of $18 \%$. The final diagnosis was inferred as "neonatal asphyxia, pneumonia, multiple organ dysfunction syndrome, hypoxic ischemic encephalopathy, or intracranial hemorrhage". She finally collapsed despite resuscitation efforts. Forensic autopsy was carried out in 2 days after death. Microscopically, left main and right coronary arteries (LMCA and RCA) originated from two separate ostiums of pulmonary artery (TCAPA). No other specific changes were found.

\section{Discussion}

Normally, the coronary arteries originate from the sinus of valsalva. Origin of one or both coronary arteries from the pulmonary artery is a fetal malformation, which happens in approximately 1 of 300,000 live births [9]. The incidence of ALCAPA (also called Bland-White-Garland syndrome) was ranged 1:50,000 to 1: $300,000[10,11]$, while the incidence of the congenial heart disease and the ARCAPA was $0.25-0.50 \%$ [10,12], $0.003 \%$ respectively [12], but the TCAPA incidence remained unknown.

Previous studies discovered [5,13-14] that in utero, the umbilical vein transfers arterial blood from placenta to the body of fetus. Due to the presence of foramen ovale, arterial catheter, com- 
pressed fetal lungs, the pressure of pulmonary artery is very close toaorta. Therefore, the coronary arteries origin anomaly has no effect on the fetal. During the process of childbirth, umbilical cord blocked and expansion of alveolar causes the reduction of the pressure of pulmonary circulation, an increase of the flow of the pulmonary venous blood in the meanwhile. TCAPA cannot provide enough oxygen and blood for myocardium, leading to myocardial ischemia and hypoxia [5]. What is different from TCAPA patient is that patients of LCAPA, RCAPA can survive for long time caused by the change of pulmonary artery pressure and the establishment of an extensive intertrial collateral circulation $[13,14]$. The clinical features of the fetus suffering from TCAPA before birth can be asymptomatic, but after birth it may show symptoms such as severe myocardial ischemia and hypoxia [5].

In this report, because of short duration of death, histological examinations didn't provide proof for the ischemia of heart. The baby was in good conditions before birth. But after the baby was born, the symptoms of severe asphyxia immediately occurred, which was consistent with the above findings. Ultimately the infant died of respiratory insufficiency caused by TCAPA. She was suspected of congenital heart disease by the first doctor, but he did not take effective methods for further diagnosis. As a result, the baby was misdiagnosed as "pneumonia, encephalopathy" in the second hospital. Therefore doctors should pay much more attention to identify the TCAPA and other congenital heart diseases, in order to save the baby's life and avoid medical disputes.

Because of no signs of the umbilical cord constrictions, the cause of death by it could be excluded. Clinically, cardiac auscultation, computerized tomography scan, magnetic resonance imaging and electrocardiograms are essential for the diagnosis of TCAPA, especially coronary angiography is the "gold standard" of the diagnosis [15]. Once the disease is identified, surgery should be promptly performed to guarantee the blood supply for two coronary arteries, so as to ensure the normal function of the heart.

In conclusion, we would like to stress the importance of careful examination of the cardiovascular system in the neonate cases of sudden death.

\section{References}

[1]. Davis JA, Cecchin F, Jones TK, Portman MA (2001) Major coronary artery anomalies in a pediatric population: incidence and clinical importance. J Am Coll Cardiol 37: 593-597.

[2]. Ogden JA (1970) Congenital anomalies of the coronary arteries. Am J Cardio 125: 474-479.

[3]. Robinson JA, Maclellan-Tobert SG, Horner JM, Cetta F (2014). Pitfalls in diagnosis: suspected anomalous origin of the right coronary artery from the pulmonary artery. Tex Heart Inst J41:51-54.

[4]. Kudumula V, Mehta C, Stumper O, Desai T, Chikermane A, et al.(2014) Twenty-year outcome of anomalous origin of left coronary artery from pulmonary artery: management of mitral regurgitation. Ann Thorac Surg 97: 938-944.

[5]. Heifetz SA, Robinowitz M, Mueller KH, Virmani R (1986). Total anomalous origin of the coronary arteries from the pulmonary artery. Pediatr Cardiol 7: 11-18.

[6]. Tavora F, Burke A, Kutys R, Li L, Virmani R (2008) Total anomalous origin of the coronary circulation from the right pulmonary artery. Cardiovasc Pathol 17: 246-249.

[7]. Scholz DG, Kitzman DW, Hagen PT, Ilstrup DM, Edwards WD (1988) Age-related changes in normal human hearts during the first 10 decades of life. Part I (growth): a quantitative anatomic study of 200 specimens from subjects from birth to 19 years old. Mayo Clin Proc 63(2): 126-136.

[8]. Coppoletta JM, Wolbach S (1933) Body length and organ weights of infants and children: a study of the body length and normal weights of the more important vital organs of the body between birth and twelve years of age. Am J Pathol 9: 55-70.

[9]. Caspi J, Pettitt TW, Sperrazza C, Mulder T, Stopa A (2007) Reimplantation of anomalous left coronary artery from the pulmonary artery without mitral valve repair. Ann Thorac Surg 84: 619-623.

[10]. Keith JD (1978) Diseases of coronary arteries and aorta . In :Keith JD, Rowe RD, Vlad P (eds) Heart disease in infancy and childhood. MacMillen, New York 1014-1020.

[11]. Hobbs R, Millit H, Raghavan P, Moodie D, Sheldon W (1980) Congenital coronary artery anomalies: clinical and therapeutic implications. Cardiovascular clinics 12: 43-58.

[12]. Keith JB, Rows RD, Vlad P (1958) Heart disease in infancy and childhood. Academic Medicine 33(8): 608.

[13]. Zheng JY, Han L, Ding WH, Jin M, Zhang GZ, et al. (2010) Clinical features and long-term prognosis of patients with anomalous origin of the left coronary artery from the pulmonary artery. Chin Med J (Engl)123: 28882894.

[14]. Bellorini M, Soubrane C, Kerneis Y, Loiret J, Tonnelier M, et al. (1988) Right coronary artery issuing from the pulmonary artery: review of the literature apropos of a case. Arch Mal Coeur Vaiss81: 103-107.

[15]. Molaei A, Rastkar Hemmati B, Khosroshahi H, Malaki M, Zakeri R (2014) Misdiagnosis of bland-white-garland syndrome: report of two cases with different presentations. J Cardiovasc Thorac Res6: 65-67. 